\title{
O COTIDIANO DOS PAIS DE CRIANÇAS COM CÂNCER E HOSPITALIZADAS
}

\author{
Maria de Lourdes Custódio DUARTE ${ }^{\mathrm{a}}$, Lisiane Nunes ZANINI ${ }^{\mathrm{b}}$, Maria Noemia Birck NEDEL ${ }^{\mathrm{c}}$
}

\section{RESUMO}

O estudo busca compreender o cotidiano dos pais com criança hospitalizada em uma unidade de oncologia e hematologia pediátrica de um hospital geral. Trata-se de uma investigação qualitativa, na qual foram entrevistados 13 familiares responsáveis pelos cuidados da criança. A partir da análise temática dos dados, emergiram três categorias: alterações no cotidiano familiar; principais sentimentos vivenciados pelos pais; dificuldades no tratamento e estratégias utilizadas. Conclui-se que cada família é única e apresenta dinâmicas diferentes de organização frente à experiência de câncer, no entanto, o desafio da enfermagem é articular essas diferenças e inseri-las no cuidado, amenizando o cotidiano da hospitalização.

Descritores: Criança. Neoplasias. Serviços de saúde. Família. Cuidadores.

\section{RESUMEN}

El estudio trata de comprender la vida cotidiana de los padres con niños hospitalizados en una unidad de oncología pediátrica y hematología en un hospital general. Esta es una investigación cualitativa, en la que se entrevistó a 13 familiares cuidadores de los niños. A partir del análisis temático de los datos revelaron tres categorías: cambios en la vida diaria de la familia, los sentimientos principales experimentados por los padres, las dificultades en el tratamiento y las estrategias utilizadas. De ello se desprende que cada familia es única y tiene diferentes dinámicas de organización ante la experiencia del cáncer, sin embargo, el reto de la enfermería es articular estas diferencias e inserftarlas en la atención, lo que facilita la hospitalización diaria.

Descriptores: Niño. Neoplasias. Servicios de salud. Familia. Cuidadores.

Título: El cotidiano de los padres de los niños hospitalizados con cáncer: los retos de la enfermería.

\section{ABSTRACT}

This study seeks to understand the daily lives of parents with hospitalized children in a unit of pediatric oncology and hematology at a general hospital. This is a qualitative research, in which 13 family caregivers were interviewed. Three categories resulted from the thematic analysis: changes in daily family life; main feelings experienced by parents, difficulties in treatment and strategies used. It was concluded that each family is unique and has different organization dynamics towards the cancer experience, however, the nursing challenge is to articulate these differences and include them in the care process, thus facilitating the daily hospitalization routine.

Descriptors: Child. Neoplasms. Health services. Family. Caregivers.

Title: The daily routine of parents of children hospitalized with cancer: nursing challenges.

\footnotetext{
a Professora Assistente da Universidade Federal do Pampa (UNIPAMPA). Doutoranda em Enfermagem pela Universidade Federal do Rio Grande do Sul (UFRGS). Porto Alegre, Rio Grande do Sul, Brasil.

b Enfermeira do Apoio Gerencial do Hospital São José do Setor de Neurorradiologia Intervencionista. Porto Alegre, Rio Grande do Sul, Brasil.

c Enfermeira. Professora do Curso de Graduação em Enfermagem da UNISINOS, Mestre em Saúde Coletiva. São Leopoldo, Rio Grande do Sul, Brasil.
} 


\section{INTRODUÇÃO}

O câncer infantil corresponde a um grupo de doenças que têm em comum a proliferação descontrolada de células anormais, e que pode ocorrer em qualquer local do organismo. As neoplasias mais frequentes na infância são as leucemias, tumores do sistema nervoso central e linfomas. Também acometem crianças o neuroblastoma, tumor de Wilms, retinoblastoma, tumor germinativo, osteossarcoma e sarcomas ${ }^{(1)}$. No entanto, desde 1970, vem-se observando um aumento das taxas de cura dos tumores na infância, estando estas, atualmente, variando entre 70 e $90 \%$ dos casos, nos Estados Unidos. No Brasil, as crianças e jovens com Leucemia Linfócita Aguda (LLA) curam-se entre 70 e $89 \%$ dos $\operatorname{casos}^{(2)}$.

$\mathrm{O}$ processo de adoecimento pelo câncer em uma criança afeta as famílias que vivenciam o cotidiano hospitalar de maneira intensa ${ }^{(3)}$. Dessa forma, na última década, a figura da família tornou-se cada vez mais frequente devido à humanização do cuidado $^{(4)} \mathrm{e}$ às exigências legais, consolidadas pelo Estatuto da Criança e do Adolescente (ECA $)^{(5)}$ e no Conselho Nacional dos Direitos da Criança e do Adolescentes (CONANDA), que transformaram em direito da criança e do adolescente permanecerem acompanhados nas instituições de saúde ${ }^{(6)}$.

Os pais, ao vivenciarem o cotidiano da hospitalização de um filho em uma unidade oncológica, inserem-se em uma nova realidade, que lhes desperta inúmeros e diferentes sentimentos. A dificuldade de interpretação desses sentimentos pelos profissionais de saúde gera, muitas vezes, dificuldades na comunicação entre a família e a equipe ${ }^{(7)}$. Ressalta-se que o processo de hospitalização provoca estresse na família e na criança. Além disso, surgem emoções e comportamentos correlacionados ao diagnóstico, tratamento e prognóstico da doença ${ }^{(8,9)}$. Dessa forma, é de extrema importância o papel da equipe de enfermagem para lidar com os pais, relacionando a sensibilidade ao conhecimento teórico, com a finalidade de oferecer uma assistência qualificada e humanizada.

O interesse no desenvolvimento do tema surgiu durante a experiência no setor de enfermagem em unidade de oncologia e hematologia pediátrica, no qual se observou o cotidiano dos pais que vivenciavam diariamente a hospitalização do filho, à espera de informações, tratamento e da cura. Esse cotidiano era reorganizado de acordo com as rotinas hospitalares, além de ser permeado muitas vezes de solidão, sobrecarga de um único cuidador, insegurança e medo.

Verificou-se também que o posicionamento, seja de proximidade ou de afastamento, tomado pela equipe de enfermagem em relação aos familiares pode influenciar na aceitação ou não do tratamento indicado. Na medida em que vínculos são estabelecidos, informações podem ser mais bem discutidas e o cotidiano na hospitalização é amenizado. Assim, evidenciou-se a importância desta temática que trata do cotidiano dos pais de crianças com câncer e hospitalizadas.

Diante do exposto, questiona-se: como se dá o cotidiano dos pais da criança com câncer e hospitalizada?

A partir desse questionamento, o presente estudo tem por objetivo geral compreender o cotidiano dos pais com criança hospitalizada em uma unidade de oncologia e hematologia pediátrica de um hospital geral. Tem-se por objetivos específicos desvelar sentimentos, dificuldades e estratégias criadas pelos pais para o enfrentamento do cotidiano na hospitalização.

Este estudo não tem a pretensão de esgotar o assunto e sim de contribuir para a ampliação, debate e construção do conhecimento sobre o tema. Através disso, despertar o interesse dos profissionais em aprimorar suas práticas, no intuito de amenizar o cotidiano das famílias em estudo, vislumbrando-as também como núcleo que também deve ser cuidado.

\section{METODOLOGIA}

Trata-se de uma pesquisa exploratório-descritiva com abordagem qualitativa ${ }^{(10)}$, realizada em uma unidade de oncologia e hematologia pediátrica de um hospital geral do Rio Grande do Sul, que presta atendimento exclusivamente pelo Sistema Único de Saúde.

Participaram da pesquisa pais de crianças com câncer de 5 a 10 anos, que concordaram em participar do estudo, totalizando 12 entrevistas, sendo nove mães, dois pais e um casal, ou seja, 13 participantes. Utilizou-se a repetição de dados nas entrevistas como critério para delimitar o conjunto de sujeitos. O tipo da amostra foi intencional, por convite, tendo como critério de inclusão estar presente no momento da coleta de dados e a criança 
estar hospitalizada no mínimo por 20 dias, pois entende-se que este período já é o suficiente para alterar o cotidiano da família. Foram excluídos os familiares de crianças em fase terminal indicados pela enfermagem, por motivos óbvios.

Os critérios de inclusão foram os seguintes: o cuidador deveria estar acompanhando o filho durante a hospitalização no momento da abordagem, no turno da manhã, tarde ou noite, no período de coleta de dados.

A coleta dos dados ocorreu no período de julho a agosto de 2007 , por meio de entrevistas semiestruturadas, as quais foram gravadas, consistindo de três principais questionamentos: Como é o seu cotidiano durante a hospitalização do seu filho com câncer? Quais as maiores dificuldades vivenciadas? Quais as estratégias utilizadas para amenizar o cotidiano da hospitalização?

As entrevistas foram pré-agendadas e ocorreram nas dependências da unidade de internação. O tempo utilizado para cada entrevista foi de aproximadamente 40 minutos. Para preservar a identidade dos entrevistados, os sujeitos pesquisados foram identificados pela numeração de 1 a 12 e denominados de pai, mãe ou pais.

Procedeu-se à leitura integral das entrevistas, adotando-se o referencial de análise temática para apreciação crítica do conteúdo, buscando-se encontrar os trechos significativos para a constituição do conjunto de temas elencados a partir dos dados da presente investigação, em relação ao objetivo proposto ${ }^{(10)}$. Seguindo-se os passos de pré-análise e exploração do material foi possível a organização e leitura repetida do corpus de pesquisa. Posteriormente, procedeu-se ao tratamento e interpretação dos resultados obtidos, descritos em unidades de registro e de contexto, que permitiram o agrupamento de ideias relevantes em categorias, representadas por três eixos temáticos de discussão, a saber: alterações no cotidiano familiar; principais sentimentos vivenciados pelos pais; dificuldades no tratamento e estratégias utilizadas.

A pesquisa foi aprovada pelo Comitê de Ética do referido hospital, conforme Protocolo de Aprovação $n^{\circ}$ 090/07, sendo considerados os aspectos éticos envolvendo seres humanos, em conformidade com o previsto na Resolução 196/96 do Conselho Nacional de Saúde ${ }^{(11)}$. Os participantes assinaram o Termo de Consentimento Livre e Esclarecido após terem sido informados sobre os objetivos da pesquisa.

\section{APRESENTAÇÃO E ANÁLISE DOS RESULTADOS}

\section{Alterações no cotidiano familiar}

A família é o primeiro grupo social mais importante na vida do indivíduo, sendo também a primeira a sentir, diretamente, as consequências de uma hospitalização, seja ela de adulto ou de uma criança $^{(12)}$. Nesse sentido, o dia a dia da família passa por uma série de alterações, além de sentimentos como medo e ansiedade com o adoecimento e com a hospitalização fazerem parte desse novo cotidiano ${ }^{(13)}$. Assim, os efeitos da hospitalização transcendem a doença e acabam alterando o cotidiano e a estrutura familiar.

O conjunto das falas possibilita verificar que, além das inúmeras dificuldades enfrentadas com a situação da doença, os pais ainda lidam com as questões econômicas devido aos grandes gastos, como: passagens de ônibus, alimentação, hospedagem. A renda familiar, constituída pelo salário do casal, muitas vezes fica reduzida, pois um membro acaba assumindo os cuidados da criança.

Eu trabalhava, mas agora mudou toda a minha rotina por causa dela. Não posso trabalhar (MÃE 1).

Meu marido pediu pra demitirem ele de uma empresa que ele já estava há 10 anos para pegar o dinheiro pra vir pra cá. Todos os 10 anos de serviço dele foi todo no tratamento do nosso filho (MÃE 2).

As famílias sentem-se ameaçadas, inseguras e desconfortáveis com a situação de não poder trabalhar e arcar com os custos do tratamento. Muitas famílias vêm do interior do estado e ainda defrontam-se com gastos como o de hospedagem e transporte ${ }^{(14)}$.

Quando um integrante da família fica doente, todos os outros são afetados, o que com frequência gera tensão, estresse e fadiga dentro do contexto familiar, principalmente entre aqueles responsáveis pela realização dos cuidados ${ }^{(12)}$. A desestruturação do mundo da família desencadeia-se na luta pela manutenção da vida do filho, gerando conflitos, desencontros e rupturas, por vezes irreversíveis, o que é apresentado a seguir:

Não vou mais para casa, vivo com a minha filha aqui

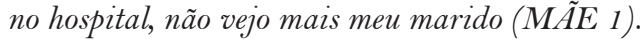


Eujá moro aqui no hospital, minha vida é aqui. Deixei meu marido, meus filhos. Meus outros filhos ficam pedindo por mim, mas não posso deixar ela aqui sozinha (MÃE 1).

Não consigo me afastar um minuto daqui do quarto, preciso ver se está tudo bem, se nada vai acontecer... Nem consigo me alimentar (MÃA 2).

Os pais sentem-se na obrigatoriedade de ficar o tempo todo do lado do filho, sem sair, nem mesmo para se alimentar. Dessa forma, a criança e a família passam a fazer parte do mundo do hospital. Novos papéis são assumidos pela família e a função de cuidar da vida da criança exercida pelos pais é reforçada. A família ${ }^{(15)}$ estrutura-se para oferecer condições à criança para manter e desenvolver suas potencialidades existenciais. Em consequência, alteram-se papéis e o modo de ser da família é abalado.

A doença é um episódio na vida da pessoa e de sua família que provoca a ruptura dos referenciais, forçando-os a se adaptar à nova realidade ao ingressarem em outro mundo, o do hospital, constituído de elementos diferentes da vida cotidiana. O ser doente e sua família adotam os referenciais pré-estabelecidos pela instituição a fim de situar-se neste mundo novo ${ }^{(15,16)}$.

Na categoria analisada, pode-se constatar que muitas alterações ocorrem na estrutura familiar no momento em que se percebem diante de um membro doente. Essas alterações afetam as relações familiares, da vida pessoal, do trabalho e até mesmo na própria relação de pais e filhos, pois eles estão vivenciando uma nova fase de descobertas e inseguranças, onde o principal foco é a preservação da vida.

\section{Principais Sentimentos vivenciados pelos pais}

Esta categoria analisa os principais sentimentos relatados pelos pais durante o cotidiano da hospitalização e tratamento do filho. O medo, a depressão e a culpa estão presentes diariamente na vida dos pais, fazendo com que estes se sintam incapazes diante da doença. Tais sentimentos estão associados à preocupação em relação ao futuro do filho no que se refere, principalmente, ao tratamento, às relações interpessoais e aos aspectos profissionais.

O sentimento de medo foi verbalizado com maior frequência entre os pais, caracterizado também como pânico, pavor, preocupação, insegurança, ansiedade, nervosismo, aflição, intranquilidade, angústia, desespero, susto e receio. Os pais vivenciam intenso medo de perder o filho, frente ao estresse da doença, acrescido do significado que têm para eles o hospital e tudo o que o filho necessita.

É um medo muito grande de perder ele, uma revolta, um pânico, um desespero, mas tô levando a vida (MÃE 2).

E quando o médico disse que era câncer foi uma sensação horrorosa, fiquei com muito medo, morria de medo de perder ele (MÃE 2).

O contato inicial com a doença gera nos pais receio do desconhecido. Muitas vezes eles verbalizam não acreditar no diagnóstico de câncer, e o receio da perda do filho surge quase que de imediato $^{(17)}$. O medo também é caracterizado pelo sentimento de insegurança diante da mudança de rotina e pelas consequências do tratamento. Cada família apresenta suas próprias características, suas maneiras de agir e enfrentar a descoberta do câncer e a hospitalização do filho, pois são seres únicos, devendo ser respeitados e compreendidos na sua maneira de ser.

A notícia de que a criança tem câncer ocasiona uma desestruturação na família, gerando situações conflitantes. A criança deixa, temporariamente, de realizar as atividades que fazem parte de seu mundo, como ir à escola e brincar, e o seu universo passa a ser o tratamento, as rotinas, as consultas e o hospital ${ }^{(9,16)}$.

A criança com câncer e a sua família deparamse com estigmas e mitos que essa doença traz, provocando impactos nesses indivíduos. Durante todo o processo de hospitalização os pais acabam vivenciando o sentimento de culpa pelo fato da criança estar doente e hospitalizada. Comprova-se esta questão nos relatos a seguir:

O sentimento que temos é uma mistura, é revolta, é uma sensação de impotência... ficava me perguntando: Onde será que eu falhei, será que fui eu que deixei acontecer isso com meu filho?Por que ele e não eu?(MÃE 2).

Isso é castigo, se eu tivesse levado ela antes no médico, ela não estaria passando por isso, me culpo até hoje, não acredito (MÃE 10).

As famílias deparam-se com estigmas e mitos da doença que permeiam o imaginário social, provocando impactos negativos no processo de aceitação do câncer. É necessário ressaltar que o câncer não 
é uma punição, castigo ou desgraça social e divina, e sim uma doença que compromete o sistema orgânico e físico, assim como não existe contágio ou contaminação por câncer ${ }^{(7,18)}$.

O conhecimento sobre a doença é de extrema importância para os pais, pois sentimentos de insegurança e de culpa podem ser minimizados com a necessidade de informação sanada, seja pelos profissionais da equipe, seja através da busca individual. Dessa forma, entende-se que é preciso esclarecer e dar informações completas aos pais sobre esses mitos, pois trazem muitas dúvidas que acabam tornando-se barreiras para entender o tratamento.

Muitos pais apresentam sintomas de depressão onde predominam os sentimentos de desesperança, impotência e desespero ${ }^{(18)}$. Cada um tem uma forma de expressar seus sentimentos, alguns isolam-se, choram e não conversam. Outros demonstram sua tristeza visualmente, pois é na aparência que muitas vezes notam-se sinais de depressão.

Eu me fechei com todo mundo, aquela depressão... Ela tem crises de choro e eu acabo me desesperando, em vez dela entrar em depressão quem entrou foi eu... nem cuido mais da minha aparência (MÃE 4).

Tô vivendo abaixo de antidepressivos, a minha vida é angustiante, não sei o que vai acontecer no dia de amanhã... já entreguei na mão de Deus [choro]... o remédio me traz mais tranquilidade, me faz esquecer um pouco do problema do meu filho (MÃE 5).

As medicações antidepressivas são muito utilizadas pelos pais, principalmente pelas mães. A literatura evidencia que são as mulheres que mais se sobrecarregam com o cuidado da criança hospitalizada ${ }^{(4,8)}$. Somado a isso, muitos pais passam por uma fase de isolamento no decorrer da hospitalização da criança, afastando-se de parentes e vizinhos, por exemplo, intensificando ainda mais os sintomas de depressão.

No que tange ao cuidado à família, a enfermagem deve identificar que essa unidade de cuidados também precisa de assistência para enfrentar os momentos de tristeza. Vale ressaltar que lidar com as reações das famílias que experienciam o processo de hospitalização da criança por câncer exige do enfermeiro uma assistência abrangente e integral. Enquanto o foco do cuidado estiver voltado somente à criança, as demandas da família não serão contempladas, especialmente quanto à exposição de seus sentimentos ${ }^{(16)}$.
A impotência diante da criança doente, a sensação de insuficiência, a expectativa de morte e a descrença nas medidas terapêuticas disponíveis refletem um tipo de paralisia diante da situação. Tal comportamento decorre da angústia pela percepção de que o câncer pode levar à morte, independente dos esforços ${ }^{(9,12)}$. Esses sentimentos tornam-se mais evidentes conforme a gravidade da doença, tempo de permanência no hospital ou a possibilidade de recidiva.

A análise desta categoria permite identificar os sentimentos vivenciados pelos pais durante as experiências de saúde e doença da criança e diante das circunstâncias que isso provoca nas relações humanas e sociais. O diagnóstico de uma neoplasia desestabiliza as estruturas familiares, mexe com o emocional das famílias, fazendo com que seus membros repensem a sua própria existência.

\section{Dificuldades no tratamento e estratégias utilizadas}

Nesta categoria serão expostos os relatos referentes às principais dificuldades no tratamento de uma neoplasia e as estratégias criadas para enfrentá-las. Com o decorrer do tratamento, a família torna-se vulnerável diante das diversas situações que a doença e o tratamento impõem. A presença dos profissionais da saúde na hora em que o tratamento é anunciado torna-se imprescindível, por isso a conduta destes deve facilitar o diálogo e a compreensão, indo ao encontro dos pressupostos da humanização.

Com o tratamento vem também uma série de informações novas, fazendo com que a família experimente estados de confusão ao presenciar situações desagradáveis no âmbito hospitalar ${ }^{(18)}$. A importância da relação entre paciente, equipe de enfermagem e família, no processo de cuidar, inclui a maneira como é dada a notícia, a clareza com que é abordado o tratamento e o esclarecimento de dúvidas ${ }^{(8,12)}$.

O tratamento quimioterápico e a repercussão que o mesmo tem sobre o físico da criança fragiliza os pais.

Não consigo olhar para ele e ver que o cabelo tá caindo, dá um dó... só Deus sabe o que eu sinto... ele passa o tempo vomitando também. [choro]. Eu me desespero, ainda bem que tem os técnicos e as enfermeiras aqui (MÃE 8).

É horrivel ver ele ficar carequinha. Eu achei que o cabelo dele não ia cair, mas agora eu vejo ele assim, é assustador (MÃE 12). 
Os pais percebem que o tratamento é necessário, porém o impacto das consequências é intenso na vida dos familiares. Os efeitos colaterais da quimioterapia $^{(14,19)}$, como vômitos e queda de cabelo, surgem como potencializadores de sofrimento no cotidiano da hospitalização. Assim, a fragilidade que uma doença crônica como o câncer impõe ao viver das famílias, considerando as intercorrências durante a quimioterapia, repercute em como a criança será tratada e enfrentará seu adoecimento e tratamento ${ }^{(14,20)}$.

O cuidado de enfermagem em Oncologia Pediátrica vem se especializando e modificando com o passar do tempo. Atualmente, a família é convidada a participar do tratamento da criança, vivenciando de maneira mais intensa o cotidiano da hospitalização. Assim, é necessário que a equipe multidisciplinar esteja mais próxima, acolhendo e escutando de forma qualificada as demandas dessa família, indo ao encontro dos pressupostos da humanização do cuidado(8).

No processo de adaptação e enfrentamento da doença, os familiares da criança com câncer passam por fases bem delimitadas, a saber: buscam enfrentar o tratamento; manter a integridade da família e o bem-estar emocional, estabelecendo suporte mútuo; e buscam por significado espiritual ${ }^{(19)}$. Dessa forma, algumas estratégias são verbalizadas pelos pais como fonte de apoio para enfrentar as inúmeras dificuldades impostas pelo tratamento e pelas repercussões que este tem na vida familiar. Acreditar em uma força superior leva muitos pais à procura de respostas e apoio na religião.

Nós somos testemunhas de Jeová, e acreditamos que nada vem por acaso, se Deus quis assim, agora temos que confiar nele. Largamos nas mãos dele (MÃE 4).

Recorri a Deus em primeiro lugar. Nos agarramos em Deus em todos os momentos (PAI 7).

$\mathrm{Na}$ maioria dos relatos, evidencia-se a crença na força divina. A fé, para as famílias, tem um importante papel no equilíbrio emocional e na aceitação da doença, proporcionando força para continuar lutando. Na busca pelo significado espiritual, muitos familiares creem na morte como vontade de Deus e passagem para uma nova vida. Pensar assim traz conformação e ajuda a suportar as incertezas quanto à recuperação da criança. Assim, a religiosidade ${ }^{(12,20)}$ aparece como uma estratégia de enfrentamento das famílias em relação ao processo saúde/doença.
Faz-se necessário que a enfermagem conheça a estrutura familiar, sua dinâmica e as interações que essa família possui e estabelece nos contextos em que transita, para assim atender às suas reais necessidades, buscando fortalecer os vínculos apoiadores utilizados pela família ${ }^{(12)}$. Esses vínculos de apoio podem ocorrer em qualquer espaço intra e extra-hospitalar, como observa-se na fala a seguir.

Eu me dou muito bem com a minha vizinha de quarto, nós trocamos experiências e é tri bom saber que não é só tu que tá passando por isso, que tem outras pessoas que entendem teu sofrimento (PAIS 11).

A troca de experiências entre aqueles que estão iniciando o tratamento e aqueles que já se encontram em fase de manutenção demonstra ser uma boa estratégia para o enfrentamento do câncer ${ }^{(12,20)}$. Muitos pais buscam nos outros a força de que necessitam, ampliando a rede de relações, mostrando-se sensíveis e dispostos a receber e doar ajuda.

A rede de apoio formada pelas famílias contribui para superar os obstáculos vivenciados no cotidiano da hospitalização de uma criança com câncer. Nesse sentido, a família é um microssistema, que se inter-relaciona com outros sistemas; é uma organização social e econômica incrustada na rede de relações, ocupando papéis em vários sistemas sociais, apoiando e cuidando de seus indivíduos integrantes. Por isso, pode ser um vínculo apoiador para os $\operatorname{mesmos}^{(12)}$.

Para esses pais, a dificuldade de conversar sobre o assunto, de entender a doença e o tratamento é superada pela articulação de estratégias, muitas vezes inconscientes, para superar a solidão e o cotidiano hospitalar. Dessa forma, a enfermagem, na relação intersubjetiva que mantém com a família da criança, pode atenuar as dificuldades encontradas pelas famílias em relação à doença e ao tratamento e potencializar estratégias de conforto, estimulando a criação de redes e vínculos que auxiliam no enfrentamento do cotidiano da hospitalização.

\section{CONSIDERAÇÕES FINAIS}

Cada família é única e apresenta dinâmicas diferentes de organização frente à experiência de câncer. Assim, ressaltamos o valor deste estudo em contribuir para a área de oncologia pediátrica, fazendo com que o enfermeiro reflita sobre a importância da inclusão da família no tratamento e no cotidiano da hospitalização. 
Nesse contexto, faz-se necessária a busca pelo equilíbrio entre o cuidado biologicista e o cuidado humanizado, uma vez que o tratamento do câncer exige a utilização de cuidados altamente técnicos os quais devem ser acompanhados do cuidado humanizado. Esse equilíbrio pode auxiliar as famílias no enfrentamento das dificuldades experienciadas neste período crítico de suas vidas.

A partir dos achados neste estudo, compactua-se com a importância de consolidar um serviço de apoio psicológico aos familiares no contexto da hospitalização, no intuito de potencializar esforços para a inclusão efetiva dessas famílias no tratamento, atendendo e entendendo suas demandas.

Finaliza-se salientando a necessidade dos cursos de enfermagem, tanto de graduação quanto de pós-graduação, abordarem mais efetivamente as demandas não só das crianças hospitalizadas, mas também de suas famílias, tendo em vista que a oncologia é uma área bastante específica e que ainda pouco explora as questões subjetivas que permeiam o cotidiano da hospitalização.

\section{REFERÊNCIAS}

1 Ministério da Saúde (BR). Câncer no Brasil [Internet]. Brasília (DF); 2007 [citado 2011 mar 10]. Disponível em: http:// www.saude.pr.gov.br/cancer/ tipos/infantil.html

2 Ministério da Saúde (BR). Instituto Nacional de Câncer. Particularidades do câncer infantil [Internet]. Rio de Janeiro: INCA; [2008] [citado 30 maio 2011]. Disponível em: http://www.inca.gov.br

3 Misko M.D, Bousso RS. Manejando o câncer e suas intercorrências: A Família Decidindo pela Busca ao Atendimento de Emergências para o Filho. Rev Latino-Am Enferm. 2007; 15(1):48-54.

4 Duarte MLC, Noro A. Humanização: uma leitura a partir da compreensão dos profissionais da enfermagem. Rev Gaúcha Enferm. 2010;31(4):685-92.

5 Ministério da Saúde (BR). Estatuto da Criança e do Adolescente [Internet]. Brasília (DF); 2006 [citado 2011 abr 08]. Disponível em: http://bvsms.saude. gov.br/bvs/publicacoes/lei_8069_06_0117_M.pdf

6 Ministério da Justiça (BR). Conselho Nacional dos Direitos da Criança e Adolescente Hospitalizado: Resolução CONANDA ¿Internet]. Brasília (DF); 1995 [citado 2010 jan 23]. Disponível em: http://portal. mj.gov.br/sedh/ct/conanda/resolu\%E 7\%F 5es/ resolucoes.pdf

7 Sales CA, Zanoni ACN, Labegalini MPC. Os sentimentos expressos pelos enfermeiros ao lidarem com a família da criança internada em uma unidade de terapia intensiva pediátrica. Nurs.2006; 94 (9):734-38.

8 Avanci BS, Góes FGB, Carolindo FM, Netto NPC. Cuidados paliativos à criança oncológica na situação do viver/morrer: a ótica do cuidar em enfermagem Esc Anna Nery. 2009; 13(4): 708-16.

9 Pedro ENR, Funghetto SS. Concepções de cuidado para os cuidadores: um estudo com a criança hospitalizada com câncer. Rev Gaúcha Enferm. 2005; 26(2): 210-19.

10 Minayo MCS. O desafio do conhecimento: pesquisa qualitativa em saúde. 10.ed. São Paulo: Hucitec; 2007.

11 Ministério da Saúde (BR), Conselho Nacional de Saúde. Resolução n. 196, de 10 de outubro de 1996: diretrizes e normas regulamentadoras de pesquisas envolvendo seres humanos. Brasília (DF); 1996.

12 Di Primio AO, Schwartz E, Bielemann VLM, Burille A, Zillmer JGV, Feijó AM. Rede social e vínculos apoiadores das famílias de crianças com câncer. Texto Contexto Enferm. 2010; 19(2): 334-42.

13 Silva FAC, Andrade PR, Barbosa TR, Hoffmann MV, Macedo CR. Representação do processo de adoecimento de crianças e adolescentes oncológicos junto aos familiares. Esc Anna Nery. 2009; 13 (2): 334-41

14. Jesus IQ, Borges ALV, Pedro ICS, Nascimento LC. Opinião de acompanhantes de crianças em quimioterapia ambulatorial sobre uma quimioteca no Município de São Paulo. Acta Paul Enferm 2010;23(2):175-80.

15 Dias SMZ, Motta MGC. Processo de cuidar a criança hospitalizada e família: percepção de enfermeiras. Rev Gaúcha Enferm. 2006; 27(4 ):575-81.

16 Poles K, Bousso RS. Compartilhando o processo de morte com a família: a experiência da enfermeira na UTI pediátrica. Rev Latino-Am Enferm. 2006; 14(2): 207-13.

17 Malta JDS, Schall VT, Modeno CM. O momento do diagnóstico e as dificuldades encontradas pelos 
Oncologistas Pediátricos no tratamento do câncer em Belo Horizonte. Rev. Bras de Cancerologia. 2009;55(1):33-39.

18 Angelo M,Moreira PL,Rodrigues LMA. Incertezas diante do câncer infantil. Esc Anna Nery. 2010;14 (2): $301-8$
19 Cicogna EC; Nascimento LC; Lima RAG. Children and adolescents with cancer: experiences with chemotherap. Rev Latino-Am. Enferm. 2010; 18(5);264-72

20 Comaru NRC, Monteiro ARM. O cuidado domiciliar à criança em quimioterapia na perspectiva do cuidador familiar. Rev Gaúcha Enferm. 2008;29(3):423-30.
Endereço da autora / Dirección del autor / Author's address:

Maria de Lourdes Custódio Duarte

Rua Gonçalves Ledo, 20, ap. 203, Partenon

90610-250, Porto Alegre, RS

E-mail:malulcd@yahoo.com.br
Recebido em: 07.07.2011

Aprovado em: 31.08 .2012 